\title{
TRANSFER OF AUSFORMING PARAMETERS TO SCALED FORGING TOOLS
}

\author{
${ }^{1}$ Bernd-Arno BEHRENS, ${ }^{1}$ Kai BRUNOTTE, ${ }^{1}$ Tom PETERSEN, ${ }^{1}$ Roman RELGE, ${ }^{1,}$ Michael TILL \\ ${ }^{1}$ Leibniz Universität Hannover, Institute of Forming Technology and Machines, Hannover Germany, EU; \\ behrens@ifum.uni-hannover.de, brunotte@ifum.uni-hannover.de,petersen@ifum.uni-hannover.de, \\ relge@ifum.uni-hannover.de, till@ifum.uni-hannover.de
}

https://doi.org/10.37904/metal.2021.4118

\begin{abstract}
Forging tools are exposed to cyclically changing thermo-mechanical stress conditions leading to its failure. Damage phenomena on the tool engraving cannot be entirely avoided by hardening the surface, as this leads to a more brittle behaviour and thus to lower ductility of the material, which can intensify the occurring damage effects. The forming of steel below the recrystallisation temperature in the metastable austenite area, known as ausforming, offers the possibility to increase strength and hardness without affecting ductile properties, due to simultaneous grain refinement.

In this study, ausforming was used to produce forging dies with increased wear resistance from tool steel X37CrMoV5-1 (AISI H11) by achieving higher hardness in the surface area while maintaining a ductile base material. Suitable forming and tempering parameters were derived from previous studies in which ausformed cups from tool steel X37CrMoV5-1 (AISI H11) with a downscaled geometry have been investigated in mechanical pulsation tests. To achieve comparable properties, a process route with adapted surface-cooling conditions, a global true plastic strain of $\varphi=0.25$ and a tempering temperature of $300{ }^{\circ} \mathrm{C}$ were applied. Further, the ausformed dies were compared with conventionally forged dies. The metallographic analysis and hardness measurements show that an increased hardness in the surface area can also be obtained for the actual formed dies. In order to see the influence of the thermomechanical alternating load on the die engraving under forging conditions, the performance of the ausformed tool will be investigated in service-life-time tests and compared to warm-formed and machined reference tools.
\end{abstract}

Keywords: Metastable austenite, ausforming, forging die inserts, wear resistance

\section{INTRODUCTION}

Hot bulk metal forming is used for industrial serial production and is considered highly efficient, since components can be produced almost without material loss in short cycle times [1]. Open die forging enables the production of simple shaped components with high mechanical performances and limited capability in terms of production volume [2]. The amount of load bearing cycles a tool system can operate without failure is decisive for the economic efficiency of the forging process and defines the tool's service life time [3]. In this context, increasing the service life time of forging tools improves the economic efficiency of the production [4]. Further, the tool's surface conditions also affects the quality of the forgings, as the damaged dies and stamps cause a change in the geometry of the manufactured product [5]. During forging operations, the active tool surfaces are subject to a superimposed cyclic thermomechanical load spectrum of high normal and shear stresses, which differ depending on the desired component geometry [6]. Furthermore, the stress type and its effect on the forging tool depend on factors like the contact condition, the workpiece temperature and the material flow [7]. These load conditions result in micro-deformations and clustering of dislocations at grain boundaries and inclusions, followed by near-surface crack formation, which propagate with each forging cycle [8]. Crack formation due to the notch effect in narrow radii in addition to abrasion and deformation is a typical failure mechanism for highly mechanically loaded hot forging dies, see Figure 1 (left). To avoid and counteract 
the described tool failure, hardness and ductility have to be increased without effecting each other negatively. This increase is limited in conventional machined and tempered steels [9]. However, if the steel is hot formed, for example by ausforming, the microstructure can be changed in texture and phase. Figure 1 (right) contrasts the textures of machined and formed dies in the radius area.

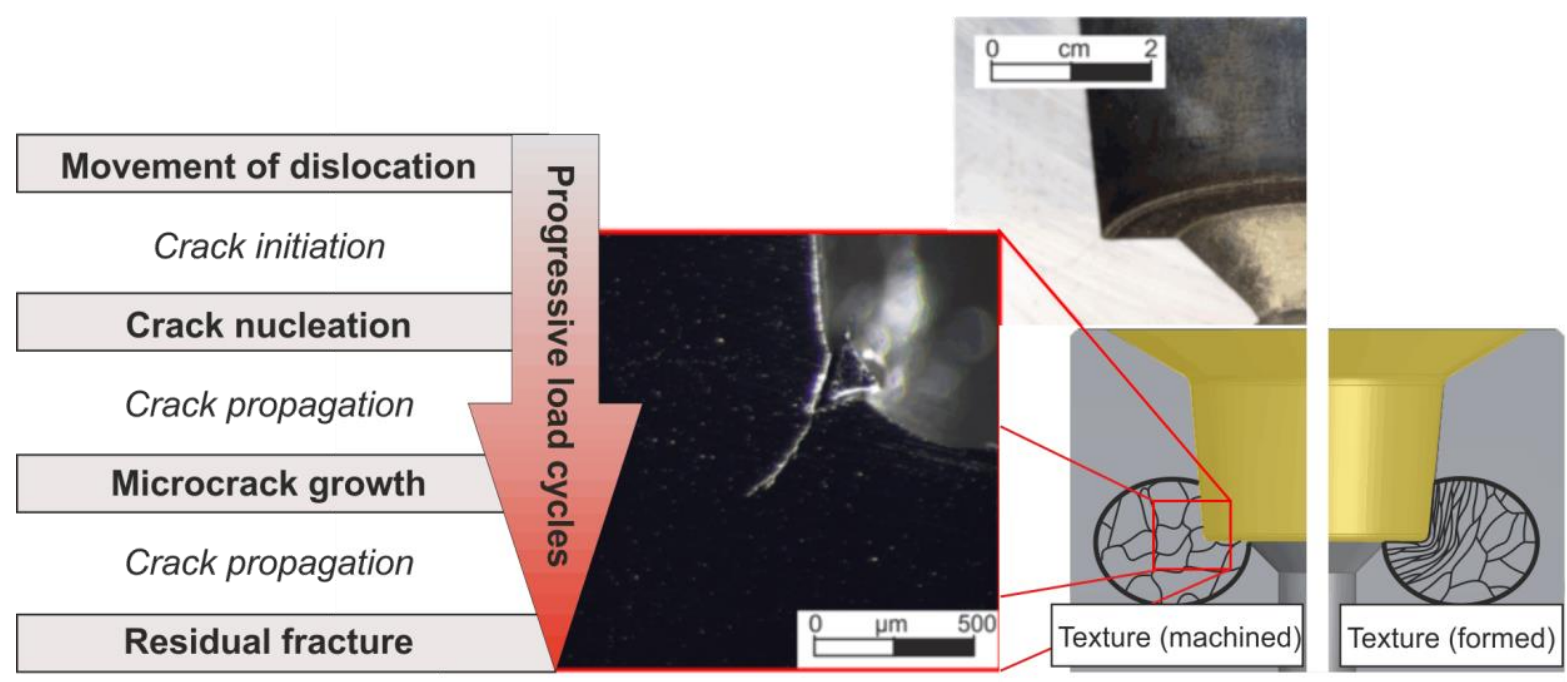

Figure 1 Defect of lower die with critical failure due to mechanical load and crack stages (left) and radius area texture of machined and formed dies (right).

The overall objective of this study is to increase the service life of forging tools by improving the microstructural properties by ausforming. Ausforming is a method of improving the above-mentioned properties, high ductility and hardness, by adapting the microstructure alignment (texture) to the actual load [10] while simultaneously refining the grains [11]. For this purpose, the steel is austenitised and then cooled to forming temperature in the metastable austenite area. During ausforming, the deformed texture in the metastable austenite phase is transferred to the martensitic microstructure in a preceding quenching treatment. The lattice defects introduced by the deformation affect the solubility, the diffusion of foreign atoms, self-diffusion and thus the nucleation and growth of the phase during its allotropic transformation. By exploiting this effect, it is possible to achieve material properties that cannot be reached by conventional methods [12]. Ausforming of highly alloyed tool steels represents an alternative to quenching and tempering of machined tool contours and allows improved properties. The combination of grain refinement and microstructural texturing should lead to an increase in service life. In previous studies [9], the fatigue life of cyclically loaded ausformed specimens of X37CrMoV5-1 (AISI H11) was investigated. For this purpose, pulsation tests were carried out to investigate the material behavior under operating conditions of alternating mechanical loads. The process variables during ausforming with $\varphi=0.25$ and tempering at $300^{\circ} \mathrm{C}$ were considered suitable. The hardness measurements revealed a different formation of the microstructure of the deformed zones. The microstructure in areas of low deformation shows similar hardness to that of conventionally quenched and tempered steels. In contrast, material zones with high deformation, such as in the radii, exhibit a finely dispersed structure that shows the highest hardness. The ausformed surface layer in the radius of the engraving reaches the hardness maximum by tempering at $500{ }^{\circ} \mathrm{C}$. Still, the elevated tempering temperature proved to be unsuitable. Due to the temperature-induced additional precipitation of carbides, the material becomes harder. As a result, the ductility and thus the fatigue life decreases due to the secondary hardening effect and increased brittleness. Nevertheless, the attained hardness is higher than with a conventional heat treatment. On the basis of the hardness measurements along the specimen cross section, it was possible to demonstrate that a lower true plastic strain leaded to higher fatigue life in pulsation tests. 


\section{METHOD AND MATERIALS}

First, the geometry of the forged die inserts was designed by upscaling the engraving from ausformed cups of previous studies [10]. For this purpose, preforms with a bottom thickness of $23.1 \mathrm{~mm}$ are forged with the die set, shown in Figure 2. The bottom thickness is decisive for the global true plastic strain while ausforming and for the material flow that occurs during forming process in the metastable austenite area. The preformed workpieces were made of tool steel X37CrMoV5-1 (AISI H11) by die forging at $1060{ }^{\circ} \mathrm{C}$ above $\mathrm{Ac}_{3-}$ temperature. This steel grade contains austenite stabilizing elements such as $\mathrm{Cr}, \mathrm{Mo}, \mathrm{V}$ and is particularly suitable for the ausforming process due to its slower transformation kinetics in the austenite phase [13]. The forging tools were also made of X37CrMoV5-1 (AISI H11) and were lubricated with Con Traer G 300, which was applied on the tools before positioning the warm preforms. For the tests, the preformed samples were austenitised for 30 minutes in a batch furnace at $1060^{\circ} \mathrm{C}$, then cooled to the temperature area of metastable austenite $\left(500{ }^{\circ} \mathrm{C}-600^{\circ} \mathrm{C}\right)$ above the martensite start temperature $\mathrm{M}_{\mathrm{s}}$ and finally ausformed with a global true plastic strain of $\varphi=0.25$. For cooling into the metastable austenite area, water is used as a cooling medium, which is sprayed onto the surface of the inner contour. The temperature at the workpiece surface is monitored by means of a thermal imaging camera, since undercooling can lead to premature phase transformation of the material and consequently to failure due to cracking [13]. However, it is not possible to cool the entire forging to a homogeneous temperature, since other material areas are not actively cooled and heat is only extracted by tool contact. The cooling water is applied with a GERLIEVA membrane spray head. Preliminary tests have already shown suitable pressure parameters for producing a uniform conical spray pattern with a controllable cooling rate. These spray parameters from preliminary tests [13] are used to prevent damage during forming. As soon as the forming temperature of $500-600{ }^{\circ} \mathrm{C}$ on the surface is reached, the preforms were ausformed using a screw press (Lasco SPR 500) and then quenched in water to room temperature. Later, the ausformed die inserts were tempered two times at $300{ }^{\circ} \mathrm{C}$ for $2 \mathrm{~h}$. As reference, die inserts were forged in a single stage forming operation at a temperature of $1060^{\circ} \mathrm{C}$ and tempered as described before.

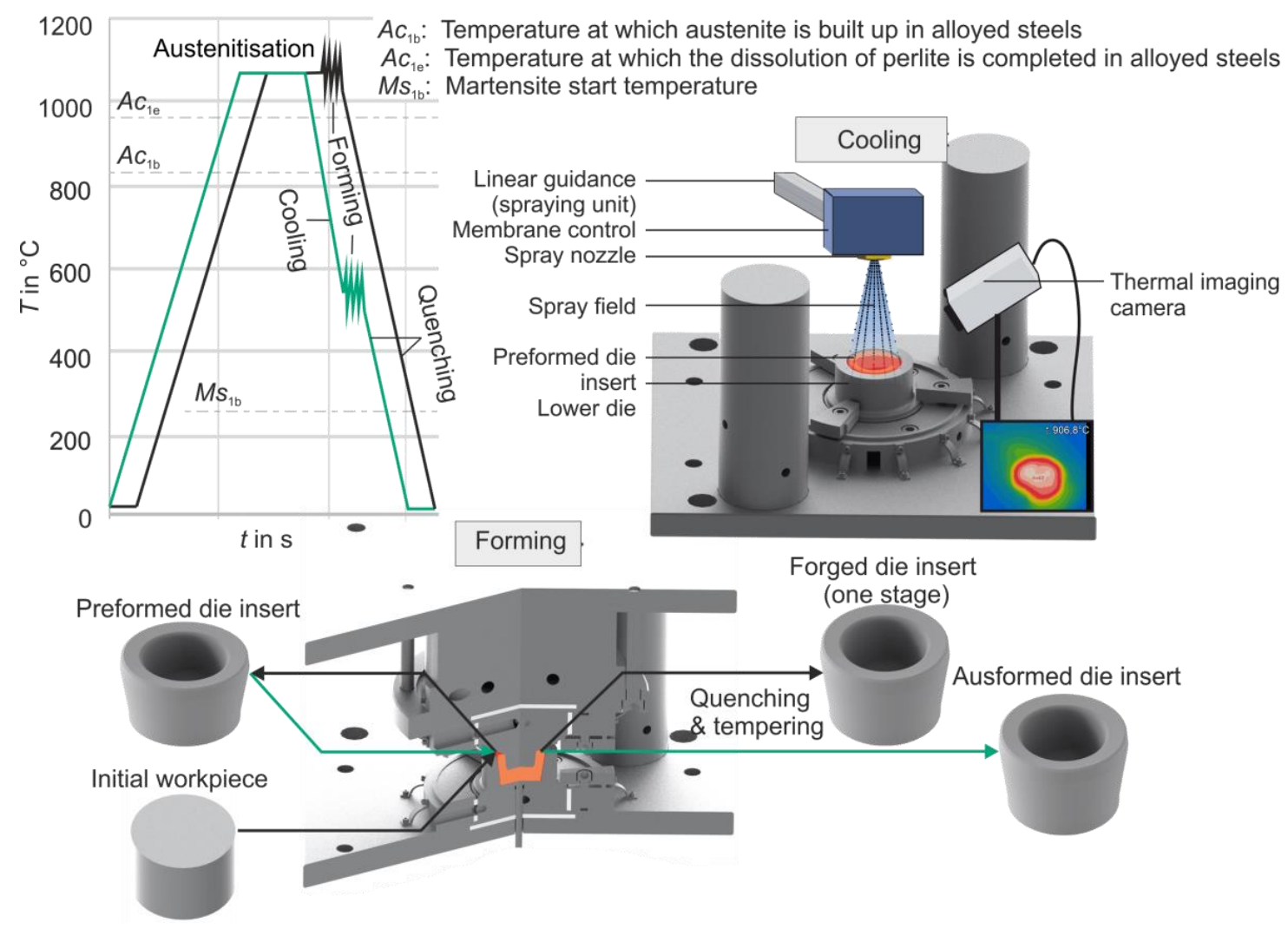

Figure 2 Ausforming process and forging tools 
To investigate the transferability of ausforming parameters to a scaled contour, hardness measurements and microstructure analysis were carried out. The specimen were cut from the centre of the formed die inserts and tested for their hardness according to Vickers (HV10). The hardness at the radius of the bottom area was investigated, as this is the area where failure occurs under alternating mechanical load. The measured hardness profiles in the radius and diagonally in depth are shown in Figure 3.

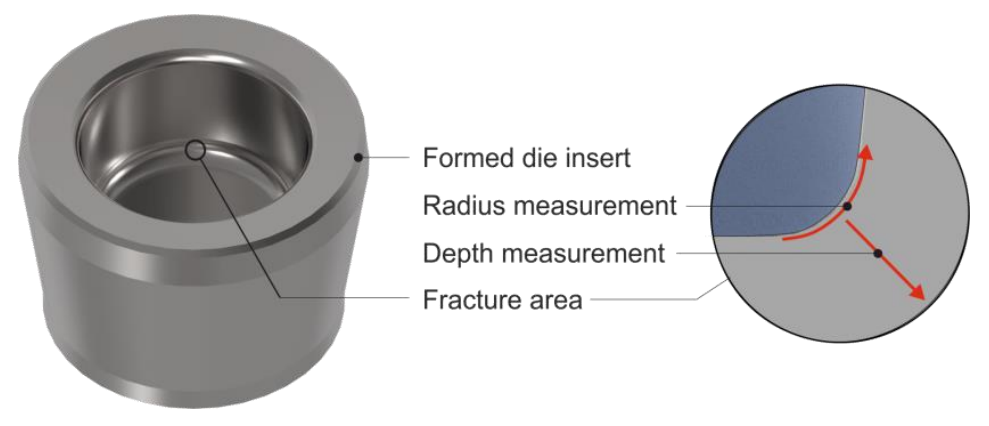

Figure 3 Hardness profiles measured in the inner radius and depth of the formed die inserts

\section{RESULTS AND DISCUSSION}

Figure 4 shows a comparison of the hardness curves of the single stage forged and ausformed die inserts. The hardness profiles in depth (left) show an increased hardness for the ausformed die inserts close to the surface. Despite the different flow stresses that occur during ausforming, due to the active cooling of the surface, a deformation-related increase in hardness can be observed. The hardness profiles of both variants converge in the depth suggesting a similar microstructure. In general, the hardness profiles show a similar course, which also indicates a comparable forming history. The hardness curve at the inner radius of the die insert (right) shows a higher hardness in the ausformed die inserts compared to the simply forged ones. The hardness, which increases from the bottom area, peaks at 660 hardness according to Vickers (HV10) at the end of the radius. Surface hardening, such as nitriding, is used in particular to increase wear resistance. This has a positive effect on the abrasion behaviour and can contribute to an increase in tool performance.
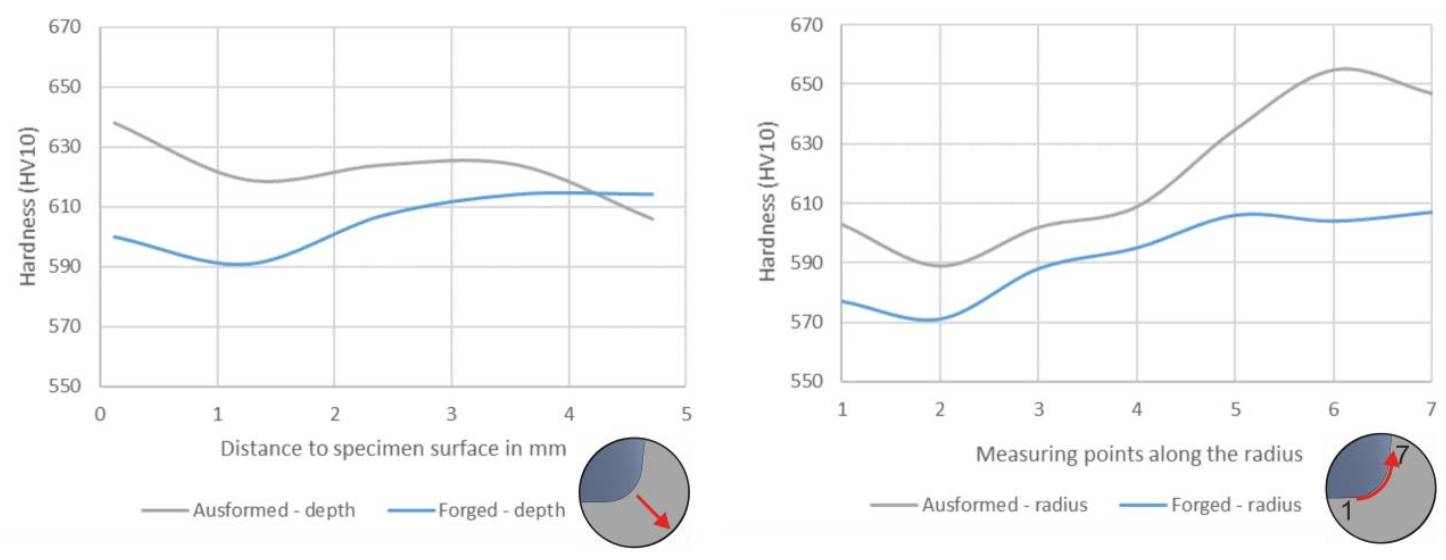

Figure 4 Hardness profile diagonal in depth of the radius (left) and along the radius contour (right) of ausformed and forged die inserts

To investigate the geometric scalability, the hardness profiles of the ausformed die inserts are compared to those of smaller ausformed cups from previous studies [9], as shown in Figure 5. Upscaling of the workpiece geometry which has to be ausformed requires a corresponding increase in the applied forming force due to the increased volume. The surface-to-volume ratio poses another challenge which influences the heating and cooling process. With the geometric upscaling of the workpiece, volume effects increase disproportionately 
compared to surface effects. The convective heating of the semi-finished products to forming temperature takes considerably longer. This bears a higher risk of edge decarburisation. At the same time, the material flow during ausforming of upscaled geometries generates larger surface area, which counteracts the effect of edge decarburisation. The cups from the previous investigation had a significantly lower volume with thinner walls and could be cooled down to the forming temperature of the metastable austenite area $(500-600 \mathrm{C})$ in $10 \mathrm{~s}$. The cooling time for the die inserts is $30 \mathrm{~s}$. The more intensive reheating of the die insert makes it impossible to set equal cooling rates. The previously mentioned flow stress gradient, which is decisive for the hardness profile, can thus not be adjusted in upscaling. The longer holding time of the hot preforms while cooling in the die and the higher forces required also increase the thermomechanical stress on the tools. The ausformed cups achieved a higher hardness under the same true plastic strain of $\varphi=0.25$, as higher stress in the radius area during forming and a faster quenching can be assumed.

The previously carried out mechanical pulsation tests showed that specimens with a lower hardness had a longer resistance to the alternating load. The higher ductility in the die ground material should be particularly advantageous. Therefore, a tendency can be derived from the reached hardness in the surface area.
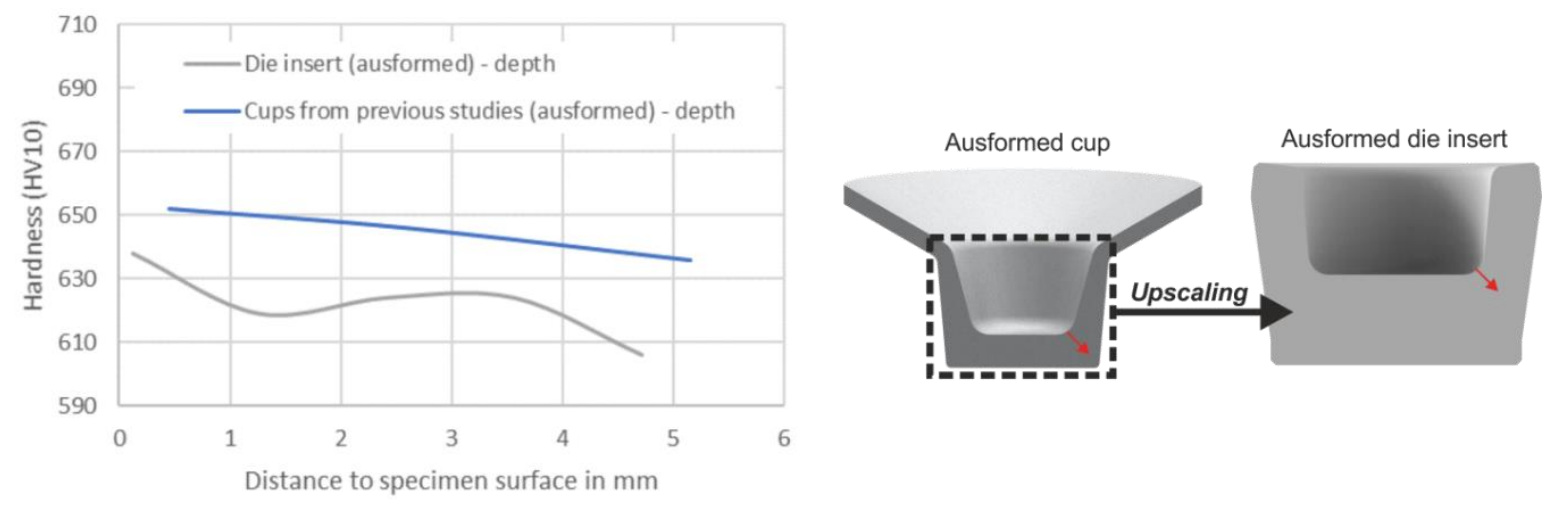

Figure 5 Comparison of the hardness profiles in depth of ausformed die inserts and ausformed cups

Figure 6 shows the microstructures of the ausformed die inserts (left) and ausformed cups in the radius area (right). It can be seen that approx. $1 \mathrm{~mm}$ below the surface, a material flow caused by the forming leads to a wave-like characteristic of the microstructure. In contrast to the rest of the microstructure, which was stretched by forming, non-deformed texture areas can still be seen. The hardness measurements correlate with the texture from the micrographs. The martensitic structure of the ausformed die insert, see Figure 6 , is finer than that of the ausformed cup. The increased hardness achieved in the cup is reflected in a noticeable higher martensite development. This indicates that the thermomechanical treatment took place under deviating conditions. However, the finer martensite structure and the lower hardness of the die inserts should have a positive effect on the tool life via less brittle behaviour under mechanical load.

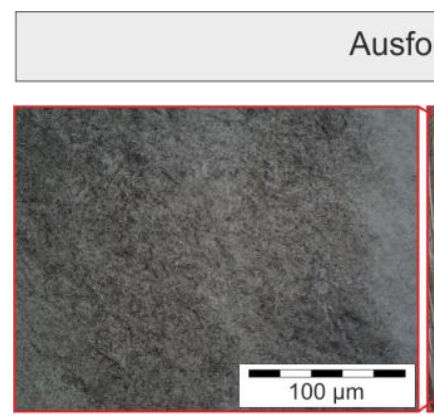

Ausformed die insert

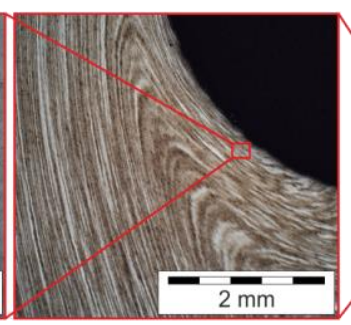

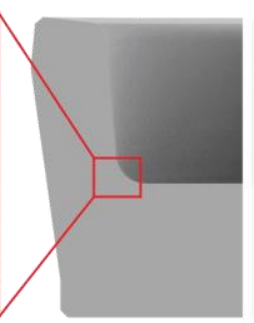

\section{Ausformed cup}

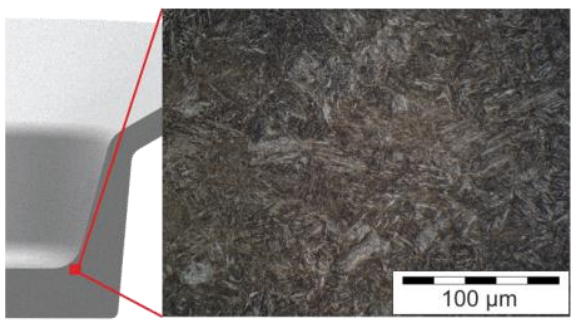

Figure 6 Comparsion of the ausformed die insert (left) and ausformed cup (right) microstructure 


\section{CONCLUSION}

Ausforming of large volumes poses a challenge, as the up-scaling results in higher required forming forces but also loads on the tool. Despite the longer heating time, no decarburisation of the surface area can be detected. Due to the geometry-related different heating and cooling times, it can be stated that a transfer of the forming parameters and the tempering step to a scaled semi-finished product geometry is hardly possible. The cooling rate of the spray cooling decreases due to a low surface-to-volume ratio compared to the process conditions of the cups from the preliminary study, which is noticeable in the hardness maxima. Thus, both the hardness gradients and the maximum hardness differ, the latter being slightly smaller in the case of the die insert compared to the previous tests. Further, a more ductile layer underneath the ausformed die engraving suggests a positive influence under alternating load and thus a favourable application behaviour. In future investigations, the suitability of the die inserts for the forging process will be tested by means of service-lifetests in order to investigate their resistance to thermomechanical loads under real forging conditions.

\section{ACKNOWLEDGEMENTS}

\section{The authors would like to thank the German Research Foundation (DFG) for the financial support of the project (Project-Nr. 318628894)}

\section{REFERENCES}

[1] ALTAN, T., NGAILE, G., SHEN, G. Cold and hot forging: Fundamentals and applications. Materials Park, OH: ASM International; 2010.

[2] CAMPI, F., MANDOLINI, M., FAVI, C., CHECCACCI, E., GERMANI, M. An analytical cost estimation model for the design of axisymmetric components with open-die forging technology. The International Journal of Advanced Manufacturing Technology. 2020, vol. 110, no. 7-8, pp. 1869-1892.

[3] BEHRENS, B.-A. Finite element analysis of die wear in hot forging processes. CIRP Annals. 2008, vol. 57, no. 1, pp. 305-308.

[4] BUCHMAYR, B. Damage, Lifetime, and Repair of Forging Dies. BHM Berg- und Hüttenmännische Monatshefte. 2017, vol. 162, no. 3, pp. 88-93.

[5] HAWRYLUK, M. Review of selected methods of increasing the life of forging tools in hot die forging processes. Archives of Civil and Mechanical Engineering. 2016, vol. 16, no. 4, pp. 845-866.

[6] PASCHKE, H., YILKIRAN, T., LIPPOLD, L., BRUNOTTE, K., WEBER, M., BRAEUER, G., BEHRENS, B.-A. Adapted surface properties of hot forging tools using plasma technology for an effective wear reduction. Wear. 2015, no. 330-331, pp. 429-438.

[7] GRONOSTAJSKI, Z., KASZUBA, M., POLAK, S., ZWIERZCHOWSKI, M., NIECHAJOWICZ, A., HAWRYLUK, M. The failure mechanisms of hot forging dies. Materials Science and Engineering: A. 2016, vol. 657, pp. 147-160.

[8] ROOS, E., MAILE, K., SEIDENFUß, M. Werkstoffkunde für Ingenieure: Grundlagen, Anwendung, Prüfung. 6th ed. Berlin: Springer Vieweg; 2017.

[9] BeHRENS, B.-A., BRUNOTTE, K., PETERSEN, T., OSTERMEYER, C., TILL, M. Adjusting Mechanical Properties of Forging Dies Produced by Ausforming. ESAFORM 2021. 2021.

[10] BEHRENS, B.-A., DOEGE, E., SPRINGUB, B. Transformation Induced Martensite Evolution in Metal Forming Processes of Stainless Steels. Steel research international. 2004, vol. 75, no. 7, pp. 475-482.

[11] DIRNFELD, S.F., KOREVAAR, B.M., SPIJKER, F. The transformation to austenite in a fine grained tool steel. Metallurgical Transactions. 1974, vol. 5, no. 6, pp. 1437-1444.

[12] WEIßBACH, W., DAHMS, M., JAROSCHEK, C. Werkstoffkunde: Strukturen, Eigenschaften, Prüfung. 19th ed. Wiesbaden: Springer Vieweg; 2015.

[13] BEHRENS, B.-A., BRUNOTTE, K., TILL, M. Manufacturing of High-Performance Forging Dies by Ausforming. In: METAL 2020 Conference Proeedings. TANGER Ltd, 2020, p. 203-208. 